\title{
ACOLHIMENTO UNIVERSITÁRIO AOS CALOUROS DE PSICOLOGIA: UMA POSSIBILIDADE DE INTERVENÇÃO
}

DOI: $10.5935 / 1984-9044.20200029$

\section{Márcia Gisela de Lima, Felipe Padilha - Universidade do Vale do Itajaí (UNIVALI)}

Resumo: Este relato descreve uma experiência de recepção universitária desenvolvida com os calouros de Psicologia em uma universidade no Vale do Itajaí. A intervenção objetivou o acolhimento e a recepção dos calouros, a fim de orientá-los sobre a formação e o mercado de trabalho. A prática foi estruturada em seis encontros com vivências, rodas de conversa, apresentação das oportunidades oferecidas pela instituição, como bolsas e projetos de extensão, e visitas aos laboratórios do curso, além de oficinas sobre demandas emergentes. Neste relato, estão descritas as técnicas e procedimentos adotados, além dos momentos mais significativos dessa prática. Como resultados, foram observados o fortalecimento de vínculos e o desenvolvimento de estratégias de enfrentamento às dificuldades apresentadas pela vida acadêmica, que prepararam os discentes para a profissão.

PALAVRAS-CHAVE: Psicologia; universidade; recepção de calouros.

\section{UNIVERSITY ACCOMMODATION TO HEALTHCARS OF PSYCHOLOGY: A POSSIBILITY OF INTERVENTION}

\begin{abstract}
This report describes an experience of university reception developed with the freshmen of psychology at a university in Vale do Itajaí. The intervention aimed at welcoming and receiving freshmen, to guide them on training and the labor market. The practice was structured in six meetings with experiences, conversation circles, presentation of opportunities offered by the institution, such as scholarships and extension projects, and visits to the course laboratories, in addition to workshops on emerging demands. This report describes the techniques and procedures adopted, in addition to the most significant moments of this practice. As a result, strengthening of bonds and development of coping strategies to the difficulties presented by academic life were observed, which prepared students for the profession.
\end{abstract}

KEY WORDS: Psychology; university; freshman reception 


\section{Introdução}

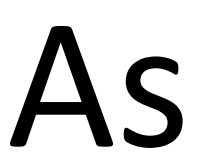

vivenciadas no primeiro

ano na universidade são

fatores importantes

para a permanência ou não dos estudantes no cenário acadêmico. A vida de um calouro é marcada por muitas mudanças: há a alegria do ingresso ao ensino superior, em contrapartida, as incertezas e medos da nova rotina, bem como as dificuldades para se integrar com os diferentes colegas e docentes do curso escolhido. Muitos estudantes saem da sua cidade, ficando longe de suas famílias e, muitas vezes, são forçados a viver com pessoas desconhecidas, tendo então responsabilidades e obrigações que antes não existiam.

Mesmo que tenham acabado o ensino médio há pouco tempo, a dinâmica da universidade é totalmente diferente para eles. Adaptar-se a esse novo contexto pode ser desafiador. Ser universitário é aprender a aprender de outra maneira; é descobrir que a didática dos novos professores é bastante diferente daquela dos antigos docentes do ensino médio e especialmente do cursinho prévestibular (Bellodi, 2004).

Tendo em vista essa realidade e as implicações em adentrar no ensino superior, considerou-se a necessidade de relatar os resultados do Estágio Básico do 6o período do curso de Psicologia da Universidade do Vale do Itajaí, visando ao acolhimento dos recém-chegados, mas que poderia ser adaptado a qualquer graduação e pós-graduação. Aqui, apresentou-se uma série de atividades que foram planejadas e desenvolvidas com os calouros do curso de Psicologia do primeiro semestre do ano de 2018, buscando acolher, criar boas impressões e expectativas referentes ao mundo acadêmico, esclarecer dúvidas pertinentes à graduação, bem como integrá-los aos ambientes da instituição, demonstrando as inúmeras oportunidades disponíveis.

Além de acolher os discentes, foram abordadas também demandas variadas, 
como tramas familiares, problemas de aprendizagem, dificuldade de adaptação com a nova rotina, sentimento de deslocamento, sensação de não pertencimento e crises de identidade relacionadas à escolha profissional.

O princípio do estágio básico em recepção de calouros é receber os novos alunos do curso de Psicologia, a fim de integrar os estudantes ao ambiente universitário e esclarecer sobre o lugar que eles ocupam nesse ambiente, esclarecê-los sobre seus direitos e deveres, bem como apresentar-lhes as diversas ações feitas pela Universidade. Sua prática teve a duração de um semestre e os encontros ocorreram semanalmente, durante as aulas de Ambientação Profissional 1, uma disciplina da matriz curricular número 9 do primeiro período do curso.

A principal queixa inicial dos calouros atendidos pelo programa de acolhimento foi a insegurança quanto à escolha profissional, que é influenciada por variáveis de diferentes naturezas (psicológica, familiar, social, econômica, cultural, entre outras). Com frequência, tal escolha é tomada de forma não reflexiva e é determinada, sobretudo, por hábitos padronizados e/ou pelos desejos de pessoas significativas na vida pessoal de cada um (Uvaldo \& Silva, 2009). O sentido do acolhimento se faz na carreira acadêmica e profissional, pois trabalhar essas questões auxilia a construir direcionamentos futuros (Dias \& Soares, 2009).

Considerando o alto índice de evasão e troca de cursos no ensino superior, entende-se que essa discussão é necessária, pois faz emergirem aspectos da escolha profissional e projeto de vida. Para Faria, Pinto e Taveira (2014), os modelos de orientação de carreira com universitários incluem diferentes tipos de conteúdo (controle da ansiedade e nervosismo, medo de falhar, estratégias de busca por emprego, escolha de carreira e competências de gestão do tempo), mas, normalmente, visam auxiliar o universitário a desenvolver autonomia para a tomada de decisões na maturidade profissional, aumentando a autoconfiança, segurança, adaptabilidade, superando a 
ACOLHIMENTO UNIVERSITÁRIO AOS CALOUROS DE PSICOLOGIA: UMA POSSIBILIDADE DE INTERVENÇÃO

procrastinação e atenuando comportamentos derrotistas.

As universidades que possuem disciplinas de orientação ou intervenção de carreira abordam questões pontuais de mercado, discutem sobre o assunto, sobre o autoconhecimento e empreendedorismo, possuem dicas de confecção de currículo e comportamentos relacionados à entrevista de seleção (Viriguine, Krawulski, D'Avila \& Soares, 2010).

Para Teixeira, Dias, Wottrich e Oliveira (2008), é importante que os cursos criem o hábito de estimular a integração social dos estudantes, pois os grupos têm como papel fundamental a construção da identidade e da rede de apoio. A forma como o calouro é recebido e acolhido interfere no processo de pertencimento à universidade e pode ser definitiva na sua relação com a qualidade do curso e sua permanência na instituição.

Para alguns alunos, entrar no ensino superior e se reconhecer como acadêmicos tem uma importância maior do que exclusivamente a escolha da profissão (Teixeira, Dias, Wottrich \& Oliveira, 2008). Assim, a metodologia adotada também buscou trabalhar aspectos da identidade de grupo, consistindo em uma sequência de atividades que seguiu um cronograma pré-estabelecido para as duas turmas do primeiro período do curso de Psicologia do horário noturno, com encontros semanais de 2 horas

maneira idêntica, não sendo necessária a descrição de atividades separadas para cada uma delas. Houve, ao total, 12 encontros (6 para cada grupo), com o
Foram alvo das práticas do estágio em recepção dos calouros duas turmas iniciais, intituladas aqui como Turma A e Turma B. As práticas ocorreram de

\section{Metodologia}


mesmo teor, porém duplicados. As análises metodológicas e os resultados foram agrupados em um mesmo conteúdo que engloba as duas turmas. Somando-os, totalizam 77 calouros entre 16 e 31 anos de idade.

\section{Atividades realizadas}

\author{
A Tabela 1 identifica os temas abordados \\ e a divisão dos encontros. A análise dos \\ conteúdos foi realizada a partir da \\ descrição das atividades, principalmente
}

na devolutiva do último dia de prática, bem como dos registros de avaliação do acolhimento realizados pelos próprios calouros.

Tabela 1. Descrição dos encontros e das atividades realizadas

\begin{tabular}{|c|c|}
\hline Tipos de intervenção & Encontros e atividades realizadas \\
\hline Dinâmicas & $\begin{array}{l}\text { 10 encontro - Integração, dinâmica de apresentação, vivência } \\
\text { do olhar e dinâmica da caixa (adaptada). }\end{array}$ \\
\hline \multirow[t]{2}{*}{ Rodas de conversa } & $\begin{array}{l}\text { 2o encontro - Roda de conversa sobre as oportunidades } \\
\text { oferecidas pela instituição de ensino. Foram abordados temas } \\
\text { como intercâmbio, bolsas de estudo, tour virtual pelo portal do } \\
\text { aluno da instituição, organização dos livros e modos de } \\
\text { empréstimo da biblioteca do campus, intranet e sistema digital } \\
\text { de inscrição de eventos. }\end{array}$ \\
\hline & $\begin{array}{l}\text { 3o encontro - Roda de conversa sobre as oportunidades } \\
\text { oferecidas pela instituição de ensino. Foram abordados os } \\
\text { temas NAU, NELLE e LDH. }\end{array}$ \\
\hline $\begin{array}{l}\text { Visitas ao espaço físico da } \\
\text { Universidade }\end{array}$ & 4 ㅇe encontro - Visita à clínica de psicologia. \\
\hline Palestra & $\begin{array}{l}\text { 5o encontro - Palestra com egressa abordando o tema: Saúde } \\
\text { mental do discente no meio acadêmico. }\end{array}$ \\
\hline Atividade prática & $\begin{array}{l}\text { 6o encontro - Encerramento, avaliação dos encontros e cápsula } \\
\text { do tempo. }\end{array}$ \\
\hline
\end{tabular}




\section{Resultados e discussão}

Após a explicação dos objetivos do acolhimento e a apresentação do cronograma das atividades, foi dado

\section{Dinâmicas}

O primeiro encontro de prática foi organizado com atividades que objetivaram a integração dos participantes: dinâmica de apresentação, vivência do olhar e a dinâmica da caixa.

O material necessário para o encontro foi: uma caixa personalizada de forma que escondesse de todos os sentidos o conteúdo interno, uma barra de chocolate, um pacote com 80 unidades de bombons ( 1 para cada participante) e aparelho de som com música. início aos encontros com as dinâmicas, tornando assim o primeiro contato mais prático e vivencial.

Para o andamento das atividades planejadas, a consigna ocorreu da seguinte forma: o coordenador disponibilizou uma música de fundo no ambiente. Com todos os participantes andando pela sala, orientou que se alongassem, desde a cabeça, o pescoço, os braços, até os pés, mantendo sempre o controle da respiração diafragmática.

Segundo Ramalho (2010), esse momento inicial em atividades em grupo é importante para a diferenciação do lugar de cada um no espaço: 
ACOLHIMENTO UNIVERSITÁRIO AOS CALOUROS DE PSICOLOGIA: UMA POSSIBILIDADE DE INTERVENÇÃO

Este momento está ligado à primeira fase da matriz de identidade definida por Moreno, que é a fase da identidade do eu (eu - eu). Para esta fase, percebemos que predominam as sensações e o desenvolvimento inicial da percepção. Devem ser utilizados nesta fase os jogos sem contato físico, mais individualizados, que promovam o alívio das ansiedades e a gradativa integração grupal, tais como os jogos de aquecimento, de apresentação, de relaxamento, de interiorização e de sensibilização. O foco é maior no indivíduo e na sua localização / aceitação no grupo, na saída de um contexto social para a criação de um contexto grupal. (Ramalho, 2010, p. 88).

Após esse primeiro momento de relaxamento, os participantes foram orientados a andar em círculo na sala. Sempre que algum colega passasse ao lado, foram orientados a olhá-lo nos olhos. Essa etapa durou em torno de 5 minutos.
A segunda etapa ocorreu com a formação de duplas. Por aproximadamente 5 minutos, deveriam ficar todos parados e em silêncio, olhando, frente a frente, nos olhos do outro.

Ao finalizar o aquecimento, pediu-se que todos fizessem um círculo na sala para o fechamento do primeiro momento. A partir do que relataram os participantes, pôde-se observar o efeito produzido com as atividades propostas, pois essa vivência promoveu o contato, trabalhou as relações de observação, a sensação de ser observado, as inseguranças e outras sensações possíveis de serem sentidas pelo grupo.

A proposta gestáltica presente nessa vivência permitiu que os participantes desenvolvessem um melhor contato consigo mesmos, pois, no momento em que eram observados por olhos alheios, teve-se a tendência do mergulho no interior de si e uma jornada à autopercepção, promovendo autoconhecimento, motivação e perspectivas de enfrentamento, provindas do self suporte, ou o apoio de 
si mesmo. Além disso, produziu um contato mais fortalecido com os demais integrantes, fomentando a criação de vínculos (Perls, 1976).

Após o encerramento desse primeiro momento, com a música de fundo, entregou-se a caixa ao grupo e pediu-se que os participantes se acomodassem de maneira confortável. Foi entregue então ao grupo uma caixa embalada, que esconde em seu interior uma barra de chocolate. Sem saber do doce, os participantes foram informados de que dentro do depositário havia um desafio a ser cumprido e que deveriam passar, de um a um, em sentido horário no grande círculo.

Foi informado ao grupo que, quando a música parasse de tocar, o participante que estivesse segurando a caixa deveria abri-la e cumprir esse desafio. 0 coordenador saiu da sala e, depois de um certo tempo, desligou a música por meio de aparelho eletrônico do lado externo. O participante que estivesse segurando a caixa deveria então abri-la e apresentar seu verdadeiro conteúdo ao restante do grupo.
Ao perceber o verdadeiro conteúdo da caixa, o desafio é revelado: distribuir um chocolate a cada um dos participantes. Houve o compartilhamento dos participantes sobre as questões que os atravessaram nessa atividade, permitindo com que os laços de vínculo também se fortalecessem.

O objetivo dessa vivência foi trabalhar, com o grupo, a influência do contato e o medo do desconhecido. Conforme Perls (1976), o contato pode proporcionar um relativismo seguro em relação às dificuldades. Transcender tais elementos faz o sujeito se diferenciar de suas inseguranças e, com a possibilidade de awareness (tomada de consciência e ação), o enfrentamento poderá ser estipulado antes mesmo das situações aversivas.

Como fechamento, o sentido que se deu à atividade em relação à vida acadêmica foi este: por mais que a universidade proponha muitas vezes uma série de desafios desconhecidos, inéditos e acompanhados de uma série de situações que abortam a zona de conforto, ainda assim, se não forem 
ACOLHIMENTO UNIVERSITÁRIO AOS CALOUROS DE PSICOLOGIA: UMA POSSIBILIDADE DE INTERVENÇÃO

encarados, perder-se-á a chance de amadurecer, construindo novos conhecimentos. Nesse sentido, tudo o que se vive na graduação ou em qualquer novo ambiente no decorrer dessa trajetória resulta em aprendizagem.

\section{Rodas de conversa}

O segundo encontro com os calouros se deu em forma de roda de conversa. Os temas abordados foram as oportunidades oferecidas pela instituição aos alunos, como intercâmbio e bolsas de estudo, além de um tour virtual na Intranet do aluno - ambiente digital utilizado pela instituição; orientações sobre o funcionamento da biblioteca institucional e também do sistema Elis, que é uma plataforma utilizada pela Universidade para a organização de eventos. Os calouros foram convidados a sentarem em círculo e assim foi iniciada a explanação.

Apresentou-se o programa de intercâmbios da instituição e suas formas de ingresso. Para abordar as bolsas de
Segundo Ruzany (2003), desvelar essas questões pode proporcionar uma posição mais ativa perante as dificuldades, facilitando o processo de enfrentamento individual e do grupo.

estudo, foram apresentadas uma a uma, com suas respectivas formas de candidatura. Após isso, iniciou-se o tour online, o qual consistiu em acessar o próprio site da Universidade, apresentando a Intranet aos calouros e suas diversas possibilidades, entre elas o portal de Eventos (Sistema Elis), o cadastramento de horas complementares e demais informações requeridas no decorrer do processo.

O terceiro encontro teve a mesma configuração, porém com a apresentação de alguns serviços e espaços oferecidos pela instituição a todos os acadêmicos. Começou-se pelo Núcleo de Acessibilidade da Univali (NAU), que acolhe e oferece apoio aos estudantes 
ACOLHIMENTO UNIVERSITÁRIO AOS CALOUROS DE PSICOLOGIA: UMA POSSIBILIDADE DE INTERVENÇÃO

com problemas de aprendizagem, garantindo o direito de acesso e acompanhamento das atividades voltadas ao ensino e aprendizagem na academia (Univali, 2018). O Núcleo de Acessibilidade é composto por uma equipe interdisciplinar e atua no atendimento, apoio e acessibilidade, área sensorial e intelectual (Univali, 2018). Foi apresentada ainda a escola NELLE, que oferece cursos de idiomas aos alunos, sendo entregue um folder informativo produzido e distribuído pela instituição. Finalizou-se com a apresentação dos espaços físicos dos laboratórios específicos do curso de Psicologia.
Por fim, apresentou-se o setor Univali Carreiras, responsável por todas as ações relacionadas ao projeto de vida de toda a comunidade acadêmica, como divulgação de vagas de estágio e emprego, planejamento de carreira, life design e orientação profissional.

Ao mostrar aos calouros como e onde acessar determinadas funcionalidades que podem ser simples para os veteranos, promoveu-se a integração acadêmica. Nesse sentido, a recepção dos calouros buscou integrar os acadêmicos à universidade, trazendoIhes esclarecimentos e formas de encarar esse novo mundo de possibilidades que o ensino superior the oferece.

\section{Visita técnica}

O quarto encontro foi composto por uma visita à Clínica de Psicologia da Univali. Para isso, foi convidada a psicóloga responsável pelo serviço, que iniciou o contato se apresentando e destacando a história da clínica, que presta atendimentos à comunidade de Itajaí e de toda a região desde 1991, realizando orientação, aconselhamento psicológico, psicoterapia familiar, psicoterapia individual e em grupo, também apresentando a forma com que os atendimentos ocorrem. 
A psicóloga responsável citou a longa fila de espera e as desistências. Destacou que a clínica tem como objetivo principal prestar serviços à comunidade, visando a promoção e cuidado em saúde mental, prestando atendimento a adultos, adolescentes e crianças residentes no município de Itajaí e região, usuários do Sistema Único de Saúde (SUS), além dos acadêmicos de outros cursos, funcionários e professores da Univali. Explicou que todos os usuários são atendidos por estagiários, destacando os aspectos éticos e sigilosos da profissão, as diferentes linhas psicológicas utilizadas pelos profissionais na prática clínica, citando também os professores e suas respectivas abordagens. Todos os acadêmicos tiveram acesso às salas de atendimento adulto e infantil, bem como à sala de observação.

\section{Palestra}

O quinto encontro teve o objetivo de dar continuidade às atividades com os grupos de maneira interativa, trazendo
A visita técnica atingiu todas as expectativas programadas. Os calouros fizeram algumas perguntas e a turma pôde agregar conhecimentos importantíssimos à sua vida acadêmica. Segundo Diniz (2006), a “observação" é necessária e deve ser realizada em contato direto, frequente e prolongado nos contextos culturais, sendo o próprio investigador instrumento de pesquisa. Nesse sentido, a presença dos calouros na clínica permitiu que eles se familiarizassem e criassem expectativas referentes às suas futuras atividades, além de proporcionar a integração desses estudantes ao ambiente universitário e ao lugar que eles ocupariam.

uma egressa do curso para compartilhar com os alunos sua experiência na 
ACOLHIMENTO UNIVERSITÁRIO AOS CALOUROS DE PSICOLOGIA: UMA POSSIBILIDADE DE INTERVENÇÃO

graduação. O tema abordado foi a saúde mental do discente no meio acadêmico.

A convidada do dia foi uma graduada em Psicologia pela Universidade do Vale do Itajaí (Univali), mestra e doutoranda em Psicologia pela Universidade Federal de Santa Catarina, na área de pesquisa de psicologia das organizações e do trabalho, desenvolvendo projetos acerca da formação profissional. Ela desenvolveu o projeto intitulado Apoio ao discente dentro do curso de Psicologia da Univali, trabalhou como monitora do Laboratório de Avaliação Psicológica e foi bolsista do Programa de Ensino Pelo Trabalho do Ministério da Saúde (PETsaúde multidisciplinar); participou da gestão 2012 e 2013 do Centro Acadêmico de Psicologia; trabalhou como monitora da Clínica Escola de Psicologia no primeiro semestre de 2012 e foi estagiária dos Projetos de Extensão Univida e Atendimento ao Idoso em Situação de Demência nos anos de 2012 e 2013.
Foi escolhido esse tema da conversa por razões específicas: os eventos estressores vivenciados na graduação como a frustração, conflitos, pressões, mudanças e competições acarretam possíveis reações fisiológicas, emocionais, comportamentais e cognitivas, já que pesquisas com discentes vinham apontando altos índices de prevalência de sofrimento psicológico e transtornos mentais não psicóticos durante o período de formação acadêmica (Dias, 2009).

Utilizando a experiência da egressa, foi proposto um diálogo entre os acadêmicos para buscar estratégias em relação aos estressores presentes na vida universitária. Ao apresentar sua carreira aos calouros, houve a possibilidade de tornar mais familiar a prática da psicologia desde a graduação, pois para Rego (1994), o sujeito se constitui na relação com o outro, e constrói conhecimento de forma compartilhada.

\section{Atividades práticas}


O encerramento do acolhimento foi constituído pela confecção da cápsula do tempo. Nessa atividade, inicialmente, o grupo de estagiários confeccionou uma caixa para armazenar as mensagens escolhidas pelos acadêmicos do primeiro período. Foi solicitado que eles trouxessem mensagens dos pais, da família, de amigos em geral, que gostariam de armazenar simbolicamente nessa cápsula. Esse material é aberto novamente apenas no último período da graduação da turma, ou seja, depois de cinco anos. No dia do encontro, os calouros trouxeram suas cápsulas (que poderiam ser feitas de garrafas) já confeccionadas. Depois do armazenamento das mensagens e demais objetos, foram fotografados todos os alunos participantes, um a um.

Nesse sentido, para Cardoso, Silva, Nascimento e Santos (2017), o arquivo de memórias e registros é um ato simbólico cheio de significado e sentido, pois entende-se que a cápsula do tempo possui uma denotação de arquivo de memórias, classificando e redistribuindo os sentidos de maneira coerente aos significados atribuídos.

O encaminhar das atividades teve como principal objetivo orientar os acadêmicos sobre as mudanças previstas nos anos de graduação, na constituição enquanto profissionais psicólogos e nas transformações que esse caminho acarreta. Encerrou-se o estágio com o arquivo da cápsula do tempo e com um agradecimento final aos alunos, relatando os sentidos produzidos pelos encontros e pelo contato com os calouros. Um vídeo realizado com fotos e registros do que aconteceu no decorrer das atividades foi apresentado em última hora, reverberando emoção dos estagiários e dos calouros, estes agora já acolhidos.

\section{Considerações finais}


A integração e o acolhimento aos calouros na instituição se mostraram de grande valia ao sentimento dos alunos em relação à universidade. As práticas consideraram os objetivos de suprir e acolher as demandas trazidas dos calouros. Buscou-se integrá-los à instituição e esclarecer suas dúvidas sobre diversas questões do âmbito acadêmico, apresentando espaços que a Univali oferece para a formação, programas e projetos que visam facilitar a rotina de universitários.

Muito mais do que acolher, procurou-se integrar os alunos uns com os outros, com a equipe de estagiários, bem como com o espaço físico da universidade.

Por fim, o trabalho de acolhimento ao discente pode ser considerado de extrema importância ao curso de Psicologia, em qualquer realidade, por uma questão de coerência com a profissão. Acolher faz parte do dia a dia dessa profissão, em qualquer contexto e espaço. Esse estágio propiciou o desenvolvimento e aprimoramento dessa competência.
Acolher é uma possibilidade de continuar um ciclo que se multiplica à medida que essas contribuições vão trazendo reais resultados aos acadêmicos. A progressão desse sentimento é geométrica: os acolhidos tornar-se-ão, provavelmente, acolhedores no futuro.

Foi nítida a contribuição das atividades no desenvolvimento dessas pessoas, ficando claro o potencial transformador que a psicologia possui mesmo dentro de seus ambientes de formação. Percebeuse que estimular a integração social dos alunos auxilia no crescimento pessoal, constituindo-se na relação com o outro, o que faz que seus medos e angústias sejam ouvidos e compartilhados.

Percebeu-se, também, o desenvolvimento da autonomia, da responsabilidade, além do amadurecimento dos alunos enquanto sujeitos, futuros psicólogos, ainda enquanto grupo, numa rede de apoio interna, o que tornou possível preparálos de uma maneira mais humanizada para as práticas necessárias na graduação em Psicologia. 


\section{Referências}

Bellodi, P. L. (2004). O programa tutores e a integração dos calouros na FMUSP. Revista Brasileira de Educação Médica, 28 (3), 204-214.

Cardoso, A. C., Silva, C. L. C., Nascimento, N. P., \& Santos, V. R. S. (2017). Projeto cápsula do tempo: Biblioteca escolar como lugar de construção de memória. IX Seminário Brasileiro de Bibliotecas das Instituições da Rede Federal de Educação Profissional, Científica e Tecnológica, 27 (1), 1666-1683.

Dias, L. G. (2012). A saúde mental dos estudantes. Cadernos Brasileiros de Saúde Mental, 4 (9), 113-118.

Dias, M. S. L., \& Soares, D. H. P. (2009) Planejamento de carreira: Uma orientação para estudantes universitários. São Paulo: Vetor.

Diniz, A. A. P. M., \& Almeida, L. S. (2006). Adaptação à universidade em estudantes de primeiro ano: Estudo diacrónico da interacção entre o relacionamento com pares, o bem-estar pessoal e o equilíbrio emocional. Análise Psicológica, 24(1), 29-38.

Faria, L., Pinto, J., \& Taveira, M. C. (2014). Perfis de carreira: Exploração vocacional, adaptação acadêmica e personalidade. Arquivos Brasileiros de Psicologia, v. 66 (2), 100-113.

PERLS, F. S. (1969/1976). Gestalt-terapia explicada. São Paulo: Summus.

Ramalho, C. M. R. (2010). Psicodrama e Dinâmica em Grupo. Aracaju: Academia.

Rego, T. C. (1994). Vygotsky: Uma perspectiva histórico-cultural da educação. Petrópolis: Editora Vozes.

Ruzany, M. H. (2003). Oficina de ideias: Manual de dinâmicas. Rio de Janeiro: Núcleo de estudos da saúde do adolescente. 
ACOLHIMENTO UNIVERSITÁRIO AOS CALOUROS DE PSICOLOGIA: UMA POSSIBILIDADE DE INTERVENÇÃO

Teixeira, M. A. P., Dias, A. C. G., Wottrich, S. H., \& Oliveira, A. M. (2008). Adaptação à universidade em jovens calouros. Psicologia escolar e educacional, $12(1), 185-202$.

Univali (2018). Universidade do Vale do Itajaí: Sobre a Univali. Recuperado em 6 de jul. de 2018 em: < https://www.univali.br/institucional/Paginas/default.aspx $>$.

Uvaldo, M. C. C., \& Silva, F. F. (2010). Escola e escolha profissional: um olhar sobre a construção de projetos profissionais. In R. S. Levenfus \& D. H. P. Soares (Orgs.). Orientação vocacional ocupacional. Porto Alegre: Artmed pp 31-37.

Viriguine, R. N., Krawulski, E., D' Avila, T. G., \& Soares, D. H. P. (2010). Da formação superior ao mercado de trabalho: percepções de alunos sobre a disciplina orientação e planejamento de carreira em uma universidade federal. Recuperado em 26 de abr. de 20018 em: < http://revistaselectronicas.ujaen.es/index.php/reid/article/view/1020/860 >.

Recebido em: 02/08/2020 Aprovado em: $17 / 12 / 2020$ 